\title{
Affix Acquisition of Chinese English Learners: A Case Study Based on a Self-Built Corpus
}

\author{
Zhixuan Liu ${ }^{1}$ \\ ${ }^{1}$ Faculty of English Language and Culture, Guangdong University of Foreign Studies, Guangzhou, China \\ Correspondence: Zhixuan Liu, Faculty of English Language and Culture, Guangdong University of Foreign \\ Studies, Guangzhou, China.
}

Received: July 13, 2021

Accepted: August 4, 2021

Online Published: August 10, 2021

doi: 10.5539/elt.v14n9p1

URL: https://doi.org/10.5539/elt.v14n9p1

\begin{abstract}
Nowadays, theoretic and empirical research into affix acquisition in Second Language Acquisition has attracted increasing attention (Peng Tingting, 2009; Zhao Ming, 2014; Chen Jie, 2017). However, there are still few empirical studies on affix acquisition of Chinese English learners, especially from the perspective of corpus linguistics. The present research aims to find out how affixes are acquired and used in written texts by Chinese English learners. A case study was conducted based on a self-built corpus. All of the data are collected from 174 undergraduate students majoring in English at a university in central China. Compleat Lexical Tutor (v.8.3) and AntConc (v.3.5.2) are used to process and analyze the data. As is shown in the results of the research, affixes acquired and used by Chinese English learners can be divided mainly into the following categories: 1 . High-frequency affixes, such as -s, -ed, -ing, etc. 2. Intermediate-frequency affixes, such as -ly, -al, etc. 3. Low-frequency affixes, such as im-, in-, ir-, etc. Therefore, the affixes that are used most frequently are -s and -es, but prefixes are seldom used in written text. The present study is beneficial for providing a crucial reference for the instruction of vocabulary and writing in colleges.
\end{abstract}

Keywords: Chinese English learners, corpus-based approach, affix acquisition

\section{Introduction}

Vocabulary plays a significant role in the field of second language acquisition. Many studies on affix knowledge so far have achieved great success, such as Laufer (1986), Nation (1990), Meara (1997), Schmitt (1998), and so on. For most Chinese English learners, it is difficult to remember and master different kinds of words. Many students have realized the convenience and efficiency of using the knowledge of affix to master a new word. Affix knowledge is an important and useful part of vocabulary knowledge because understanding the meanings of prefixes and suffixes along with root words will enable learners to determine a word's meaning without having to look it up in a dictionary. It is helpful to enlarge learners' vocabulary through grasping the rules of affix. According to Nagy, 'Affix knowledge increases reading ability and vocabulary.' (Nagy, 1993) English teachers in China have emphasized the necessity of imparting affix knowledge to help master more words.

However, whether students have possessed the ability to put the affix knowledge into real use correctly is still unknown. English composition is a good way to reflect whether students can flexibly use what they have learned about words in real use correctly. Therefore, the present research focuses on how affixes are used in the compositions of English majors and their characteristics. The following problems are aimed to be solved.

a) What is the status quo of English affixes of Chinese English learners?

b) What are their characteristics of affix acquisition?

c) Wu Yi \& Ma Guanghui (2006) suggest that the learning of English affixes is sequential and that some affixes are more easily studied. Is this hypothesis proved in the learning process of affixes of English major students?

d) What is the enlightenment of the characteristics of English affixes to the practical instruction?

With the popularity of corpus linguistics, the corpus has been widely used in studies related to affix acquisition. In the field of second language writing instruction and research, corpus linguistics provides a new way to study 
affix acquisition more objectively based on big data. Using corpus in research and instruction can not only improve the instruction effectiveness but also can construct a new way to English writing for English instruction.

Based on affix knowledge and corpus linguistics, this exploratory study aims to find out the characteristics of affix acquisition among English majors in China, by collecting the English compositions in the final-term examination. The subjects are from three grades of the target university, respectively. Through the analysis of the self-built writing corpus by AntConc software and word analysis website (https://www.lextutor.ca/familizer/), the use of different affixes is clearly shown in compositions.

The knowledge of affix is of great importance to both language learners and language teachers. It contributes to determining how well a learner reads new words (Nagy et al., 1993). When students encounter a new word, affix knowledge can help them understand familiar prefix or suffix to know the meaning of the new word without a dictionary and can improve their ability to analyze and use words. In this way, their vocabulary can be enlarged in a relatively short time compared to remembering words one by one. As for teachers, comprehensive knowledge of affix will enable them to choose, classify, and teach linguistic material systematically, thus students can better understand and master a variety of words. In addition, teachers who resort to this method will lead students to grasp the extended vocabulary through affixes.

However, there has been little emphasis put on the acquisition of affix, let alone researches on affix acquisition based on a self-built corpus. It does not enjoy a priority in second language acquisition research. Based on this situation, more attention should be paid and more meaningful exploratory studies should be conducted.

\section{Literature Review}

\subsection{Basic Concepts}

In this part, some basic knowledge like definitions of corpus and affix are presented and previous studies related to affix acquisition are listed to get a comprehensive understanding of the subsequent analysis in this paper.

\subsubsection{Corpus}

According to the online Merriam-Webster Dictionary (Available at the website: https://www.merriam-webster.com/dictionary), the term corpus (plural corpora), refers to a collection or body of knowledge or evidence, especially a collection of recorded utterances used as a basis for the descriptive analysis of a language. The main purpose of a corpus is to observe how a particular word is used in real conversations. Corpus linguistics deals with the principles and practice of using corpora in language studies. A computer corpus is a large body that contains a lot of machine-readable texts. The importance of corpus to language study is in the empirical data which provide broad samples, extending over a wide selection of variables. This allows generalizations to be made, as the corpus is as wide and as representative as possible. There are many well-known corpora, such as CLEC (Chinese Learner English Corpus), COCA (Corpus of Contemporary American English), BNC (British National Corpus) and so on.

\subsubsection{Affix}

Affixes are forms attached to words or word elements to modify meaning or function. According to the functions of affixes, scholars divided affixes into inflectional affixes and derivational affixes. The affixes attached to the end of words to indicate grammatical relationships are inflectional affixes. In contrast, derivational affixes are affixes added to other morphemes to create new words. In terms of location in a word, derivational affixes can be divided into prefixes and suffixes $(\mathrm{Li}, 2003)$. The Longman Dictionary of Language instruction \& Applied Linguistics (2003) defines a prefix as 'a letter or group of letters or sounds that are added to the beginning of a word and that change the meaning or function of the word.' For example, the word antinuclear uses the prefix anti-, which means "opposed to". Generally speaking, the prefix does not change the word class of the base. According to the Longman Dictionary of Language instruction \& Applied Linguistics (2003), a suffix is defined as the letter or sound or group of letters or sounds which are added to the end of a word and which change the meaning or function of the word. For instance, the suffix -ward, which means towards a particular direction or place, can be used to form the word homeward.

\subsection{Previous Studies on Affix Acquisition}

The empirical studies on affix acquisition abroad began in 1997. By now, there are mainly three influential studies. Schmitt \& Meara (1997) conducted the first empirical study on the relationship between affix knowledge and other dimensions of vocabulary knowledge. It confirms the point that the derivational suffix knowledge is fit with vocabulary size. A year later, Mochizuki M. (1998a) made an empirical study on L2 learner's affix acquisition characteristics. It was asserted that some affixes were easier to acquire than others, thus he suggested 
that established order would benefit teachers who wanted to teach affixes systematically. In addition, Mochizuki and Aizama (2000) investigated the relationship between the vocabulary size of second language learners and their affix knowledge. The results showed that the affixes could be ranked in terms of accuracy order. The order of prefix is "re-, un-, pre-, non-, ex-, anti-, semi-, en-, post-, inter-, counter-, in-, ante-"; the order of suffix is “-ation, -ful, -ment, -ist, -er, -ize, -al, -ly, -ous, -ness, -ism, -able, -less, -ity, -ish, -y".

Omid Tabatabaei and Masumeh Yakhabi (2011) managed to find the relationship between morphological awareness and vocabulary knowledge. The results revealed that the students performed better at the 2000 level than at the 3000 and 5000 levels where the most frequent word families occur. Dongbo Zhang, Keiko Koda (2013) studied foreign language learners' morphological awareness and its contribution to the reading comprehension of Chinese EFL (English as a Foreign Language) learners. The results showed that the basic facet of inflectional awareness of the learners was better than that of derivational awareness. The conclusion of Dmitri Leontjev, Ari Huhta, and Katja Mantyla (2016) added to our knowledge of how the ability to derive English words developed among L2 English learners. Its findings demonstrated a relationship between word derivation knowledge and language proficiency.

Domestic scholars also did a number of contributions on affix acquisition by Chinese English learners, most of which are the researches on vocabulary acquisition, collocation, and the characteristics of a particular field, such as business English, maritime English, and EST (English for science and technology). Liu Shaolong (2001) has made studies on the relationship between affix knowledge and learners' language proficiency. The results were put forward as follows: on affix, the receptive knowledge is always larger than productive knowledge; the capability of receptive affix knowledge surpasses largely the capability of productive affix. Liu Shaolong (2002) later found that the productive capability of meaning was a moderate correlation to the productive capability of affix; the productive capability of affix was a moderate correlation to the receptive capability. The results of the study made by Cui Yanyan \& Wang Tongshun (2005) pointed out that the acquisition of derived affixes showed the characteristics of interlanguage, the characteristics of vocabulary acquisition, and the development of meta-language knowledge. Wu Yi \& Ma Guanghui (2006) considered that the prefix acquisition order of Chinese EFL learners is: 'non-, re-, un-, pre-, ex-, counter-, in-, re-, post-, anti-, ante-'; and the suffix acquisition order of Chinese EFL learners is: '-er, -ation, -ful, -ly, -ize, -able, -al, -ment, -ous, -y, -ness, -ish, -less, -is, -ity, -ism'. They also argued that learners' suffix acquisition was better than their prefix acquisition.

Wu Yi (2007) also analyzed the derivational affix acquisition order of Chinese non-English majors to describe the order characterizing the affix learning by the Chinese EFL learners as revealed from their level of receptive and productive mastery of affix knowledge. Wang Shizheng (2008) discussed the phonological and morphological properties of -ize derivatives and analyzed the influence of phonology on this suffixation. Li Xu (2010) did a corpus-based study on English verbal suffixes. Four English verbal suffixes -ify, -en, -ize and-ate have been studied from both qualitative and quantitative aspects to figure out the linguistic properties across spoken, newspaper, fiction, magazine and academic registers. It was learned that the most productive verbal in the past was -ize and the most unproductive one was -en while another measure showed that the sequence of potential productivity was-ize, -ate, -en, -ify. In addition, the verb suffixes are inclined to produce new words with adjectives and nouns, and could combine with a few verbs.

\subsection{Summary}

Based on the overview of the previous studies at home and abroad, the fact is that the empirical study of affix based on corpus is quite few. Numerous researchers focused on the relationship between affix and vocabulary, collocation, the learning order of affixes, and the receptive and productive capability of affixes. As for the features of the word itself, such as word-formation characteristics, few studies have been done, let alone corpus-based empirical studies. Therefore, this article will focus on the use of affixes by Chinese English students. With the help of corpus analysis software Antconc 3.5.2 and word analysis website Compleat Lexical Tutor (https://www.lextutor.ca/familizer/), qualitative and quantitative analysis will be done for the self-built corpus to find out characteristics of affix acquisition in written language. In addition, this study aims to give students a new way to transcend the traditional writing pattern and pay attention to the use of affixes to enlarge vocabulary. At the same time, it also gives some pedagogical implications to English writing.

\section{A Corpus Approach towards Affix Acquisition}

The first part is about how the corpus used in the present study is built for the analysis of affixes in written texts by Chinese English learners. The second part is a brief introduction to the corpus tools used in the present paper. The third part provides the procedures for data processing in detail. 


\subsection{A Self-Built Corpus}

There are many famous corpora like CLEC, BNC. Considering the numerous samples and complicated output contained by large corpora, they do play a crucial role in linguistics studies. For English teachers, it is specialized corpora that are more useful. This kind of corpus is widely used for language for specific purposes. If we need to find out what language is used in a certain profession, then we select texts from that profession. Wu Zhifang (2007), Hu Xia (2007), Xu Shuling (2011) all applied self-built corpus into lexical instruction and found that it was beneficial to promote students' study motivation. Teachers can collect the materials in the field of pedagogical research, textbooks, and instruction contents they need on purpose. In addition, it is very convenient for them to update, collect, and arrange the materials. Most importantly, a self-built corpus is especially constructed for a certain group, no matter it is for specific teachers or students. It has its feasibility in some fields. For example, in this study, the corpus is built to analyze the present situation and the lexical level of English majors.

The participants in the present study were English majors who were freshman, sophomore, and junior students in the Foreign Language Department. Students are between 18 and 24 years old, and most of them have at least 6 years of English learning experience. Additionally, neither participant received any special training on the use of affixes before taking the exam.

The first step is to collect the final examination writing papers of the Advanced English Course of three grades. Each group has 58 samples, with 174 samples in total. The type of composition is argumentative, with the same title 'Whether tablets should replace the paper textbook in school'. The purpose of using composition with the same title is to study the characteristics of affixes and their correlation with the quality of writing in a more detailed way when expressing a similar idea.

The author collected all the samples of the paper files and typed them as electronic files, at the same time, deleted the composition title, students' names and other personal information, to build the corpus needed for this study. After the corpus was built, text-proofing is a must to ensure the authenticity and validity of the data. Therefore, the data are effective statistical results.

\subsection{Data Processing}

\subsubsection{Corpus Tools}

In this study, AntConc (v.3.5.2) is used to retrieve data. It was developed by Laurence Anthony, Japan, and was widely applied in the field of corpus linguistics. It is a free and safe software concordance program for Windows. The software has seven tools: Concordance, Concordance Plot Tool, File View Tool, Clusters/N-Grams, Collocates, Word List, Keyword List. In the present study, it is mainly used to produce a Word List and to calculate the total number of word types and word tokens. The function of Word List can help count all the words that appeared in the corpus and present them in order. It can be used to find which words are the most frequent in a corpus quickly.

Compleat Lexical Tutor is an online vocabulary researching, instruction and learning website (https://www.lextutor.ca/familizer/) developed by Tom Cobb of Univerity of Quebec at Montreal (UQAM). It is used for ESL educators to employ in their classrooms to provide effective vocabulary instruction, especially in an academic context. This study uses mainly the Familizer function.

\subsubsection{Data Collection and Processing}

In the present study, first using AntConc to open all the 174 writings at the same time and get the Word List sort by word. The first grade has 1310 word types, 12956 word tokens. The second grade has 1443 word types, 12691 word tokens. The third grade has 1780 word types and 15938 word tokens. The total number of word types is 2696 and the number of word tokens is 41586 . After that, opening Compleat Lexical Tutor website (https://www.lextutor.ca/familizer/) and then using Word List to produce word families list as a reference version.

After data collection, it is necessary to process the data. Exporting the Word List and saving it as an Excel table. The next step is to check every word carefully and find out the errors. Some of the errors are caused by software which should be deleted as invalid data. While some other errors are produced by spelling, as this study mainly focuses on the use of affixes, the author corrects the misspelling words (not including the misspelling affixes and misused affixes). There are 2696 words before revising. Finally, the valid data remain 2560 words.

The final step is to tag every word after being processed. 
Table 1. A list of affixes under investigation

\begin{tabular}{|c|c|c|c|}
\hline Affixes & Meaning & Example & Tag \\
\hline negative prefixes & & & 1.1 .1 \\
\hline dis- & reversing the action & dislike & \\
\hline in- (il-, ir-, im-) & not & injustice & \\
\hline non- & not & nonsense & \\
\hline un- & not & unhappy & \\
\hline mis- & wrongly & misunderstand & \\
\hline prefixes of degree and size & & & 1.1 .2 \\
\hline co- & jointly & cooperation & \\
\hline extra- & very & extravagant & \\
\hline out- & surpassing & outrange & \\
\hline over- & excessive & overdue & \\
\hline sub- & secondary, less important & subconscious & \\
\hline super- & more than, beyond & superstar & \\
\hline sur- & over and above & surcharge & \\
\hline attitude prefixes & & & 1.1 .3 \\
\hline anti- & against, opposed to & anti-abortion & \\
\hline contra- & opposite, contrasting & contradistinction & \\
\hline counter- & against, in opposition to & counterplan & \\
\hline pro- & for, on the side off & pro-democracy & \\
\hline prefixes of time and space & & & 1.1.4 \\
\hline extra- & outside & extra-curricular & \\
\hline fore- & front part off & forehead & \\
\hline inter- & between, among & interpersonal & \\
\hline super- & above & superstructure & \\
\hline tele- & distant & telecommunication & \\
\hline ex- & former & ex-lover & \\
\hline number prefixes & & & 1.1 .5 \\
\hline bi-, di- & two & bilingual & \\
\hline multi-, poly- & many & multi-candidate & \\
\hline semi-, demi-, hemi- & half & semi-automatic & \\
\hline tri- & three & triangle & \\
\hline conversion prefixes & & & 1.1 .6 \\
\hline be- & produce predicative adjectives & asleep & \\
\hline a- & to form transitive verbs & befriend & \\
\hline en- & create transitive verbs & enable & \\
\hline intensive prefixes & & & 1.1.7 \\
\hline ac- & strengthen & accumulate & \\
\hline ad- & at, to & adequate & \\
\hline noun suffix & & & 1.2 .1 \\
\hline -er & having as dominant characteristic & teenager & \\
\hline -let & small, unimportant & booklet & \\
\hline -age & measure of, process, or state & mileage & \\
\hline -ing & the material of & tubing & \\
\hline
\end{tabular}




\begin{tabular}{|c|c|c|c|}
\hline -ship & occupation, position & governorship & \\
\hline -ation, -ition, -tion, -sion, -ion & product of & imagination & \\
\hline -ity & state or condition & productivity & \\
\hline adjective suffixes & & & 1.2 .2 \\
\hline- ful & full of, providing & helpful & \\
\hline -less & without & nameless & \\
\hline$-\mathrm{y}$ & somewhat like & flowery & \\
\hline -ous, -eous, -ious, -uous & having a particular quality & marvelous & \\
\hline -able & possibility & readable & \\
\hline adverb suffixes & & & 1.2 .3 \\
\hline$-1 y$ & in...manner, to a... degree & gradually & \\
\hline -ward, -wards & direction & downward, homewards & \\
\hline -wise & in...manner & clockwise & \\
\hline verb suffixes & & & 1.2 .4 \\
\hline -ate & make or become & validate & \\
\hline -en & make or become & strengthen & \\
\hline -ify & make, endow with" & simplify & \\
\hline -ize, -ise & involving or related to & symbolize, fantasize & \\
\hline \multicolumn{4}{|l|}{ affixes } \\
\hline -ing & progressive aspect & eating & 2.2 \\
\hline -est & $\begin{array}{l}\text { superlative degree of adverbs and } \\
\text { adjectives }\end{array}$ & smallest & 2.3 \\
\hline -er & $\begin{array}{l}\text { comparative degree of adverbs } \\
\text { and adjectives }\end{array}$ & smaller & 2.4 \\
\hline$-\mathrm{s}$ & noun plurality & goods & 2.5.1 \\
\hline$-s$ & third-person singular & jumps & 2.5 .2 \\
\hline -(e)d & shows past tense & liked, walked & 2.6 \\
\hline
\end{tabular}

\section{Affix Acquisition of Chinese English Learners: A Case Study}

We have listed the research questions and the design of this research. The following is the core of this thesis. First of all, a general discussion is presented. Then, a more detailed analysis of the concrete use of prefix and suffix is presented, respectively. Finally, potential reasons behind the used affixes are offered, mainly from two points of view, which are factors of students and factors of teachers.

After tagging, the use of affixes by English majors is clear. It can be divided into three different categories: high-frequency affixes, intermediate-frequency affixes, and low-frequency affixes.

\subsection{High-Frequency Affixes}

High-frequency affixes refer to the affixes used more than 100 times in 174 compositions. The total frequency of high-frequency affixes is 807 times. It can be further divided into four types: -s, -es; -d, -ed; -ing; -ion, -ity, -ment, etc.

\subsection{1 -s, -es}

The frequency of -s, -es is 313 , which ranks the first, such as accents, accidents, adults, and so on. The most often used word is tablets, whose frequency is 1042. Since the topic is 'Whether tablets should replace the paper textbook at school?' it is not surprising that 'tablet' ranks first. The following words are books, students, textbooks, tablets, books, students, text, books, schools, notes, devices, words, eyes, advantages, things, reasons, games, teachers, keywords, products, supplies, years, tables, ways, education, trees, disadvantages, sizes, lots, sides, dollars, papers, ourselves, phones, points, computers, thousands, times, tools, opinions, purposes, teenagers. All of these words have appeared in compositions at least ten times. The frequency below ten is not listed in this part. 
After careful analysis, the author has found some errors, not mistakes. The difference between errors and mistakes lies in the fact that the first refers to the lack of knowledge of the learners, while the latter means that the learners have already learned the knowledge, but fail to perform it correctly. According to the statistics, errors like attentions, admirations, and informations are found. It is clear that information is an error because the word is only used as an uncountable noun. There is no such a word as "an information" or "informations". However, attention can be used as both a countable word and an uncountable word. In order to determine whether it is an uncountable word, the function of Concordance in AntConc is the best solution. Searching for the word 'attentions', the author got a figure like this:

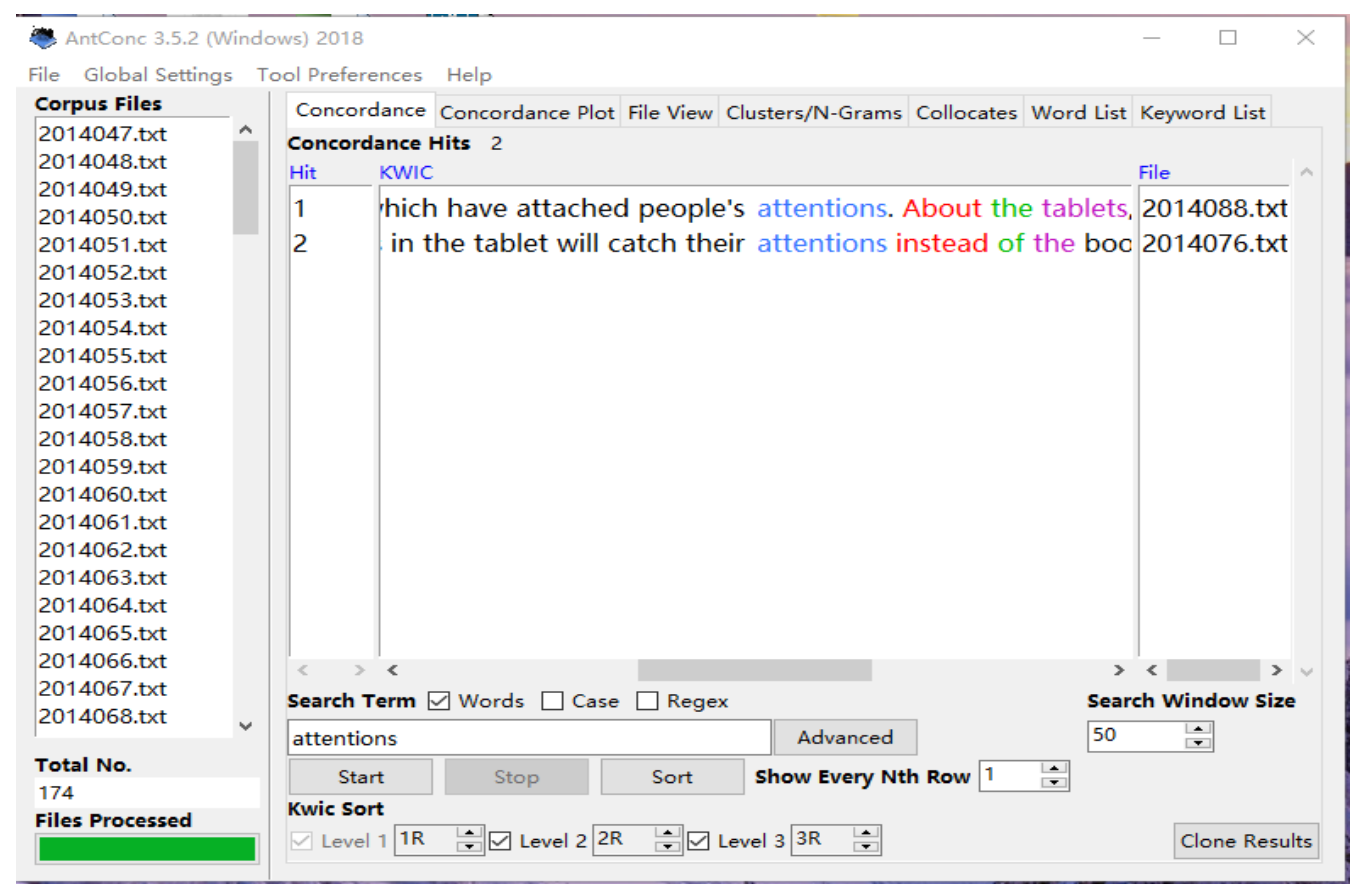

Figure 1. "attentions" in AntConc (v.3.5.2)

From the figure, we can see that "catch one's attention" is a fixed phrase and "attention" is used as an uncountable noun.

\subsection{2 -d, -ed, etc}

The frequency of - $\mathrm{d}$, -ed is 209 , which ranks second. The most commonly used word in this group is printed. It is used 411 times in total. The topic is related to tablets, so it is reasonable that the verb 'print' is shown as the most often used verb. The second often used verb is replaced, which is included in the title. It is used 97 times. The third often used verb is used, which appears 92 times. The frequency of the following verbs is sharply decreased to 35 times. Many other verbs are used only once, including absorbed, accepted, addicted, affected, affirmed, aged, agreed, appeared, applied, approved, argued, associated, based, booked, bored, called, carried, charged, checked, clicked, collapsed, completed, complicated, concluded, confronted, constructed, continued, controlled, copied, covered, cracked, damaged, debated, deepened, deluged, deprived, designed, and so on. There are also some irregular past tense words such as was, were, but their frequency is below 50 .

\subsection{3 -ing}

The frequency of -ing is 175, ranking third. 'Using' is the word most commonly used, with a frequency of 114 . After searching the word in AntConc, the collocation phrases are using a tablet, using tablets, using books, using paper books, using printed books, using textbooks, using traditional books, etc.

The second often used word in this group is reading. It is used 102 times. The third often used word is studying, and it is used 41 times. The other used past participle words are as follows: writing, becoming, learning, instruction, taking, developing, being, feeling, playing, saying, having, comparing, going, coming, providing, buying, denying, doing, following, highlighting, interesting, looking, making, printing, replacing, thinking, working, getting, investing, listening, enjoying, growing, etc. 


\subsection{4 -ion, -ity, -ment, etc}

Affixes in terms of noun suffixes such as -ion, -ity, -ment, -ence, etc are applied 110 times. The order of noun suffixes is -ion, -ity, -ment, -ence, -er, -ness, -ance. As Figure 2 shows that the most often used noun suffix is -ion, which is used 44 times. It has words such as accession, action, addition, application, argumentation, civilization, collection, communication, concentration, conclusion, connection, consideration, decoration, etc. Other noun suffixes like-ity, -ment, -ence, -er, -ness are used in words such as ability, achievement, advancement, advertisement, appearance, argument, awareness, browser, colorfulness, creativity, dependence, development, difficulty, difference, etc.

The suffix acquisition order of Chinese EFL learners put forward by Wu Yi \& Ma Guanghui (2006) is: -er, -ation, -ful, -ly, -ize, -able, -al, -ment, -ous, -y, -ness, -ish, -less, -ist, -ity, -ism. What we have found does not perfectly agree with the suffix acquisition, and the suffixes our objects use are not the same as the list put forward by Professor Wu. But it is the same conclusion that a suffix such as -ion is relatively easier to acquire by learners.

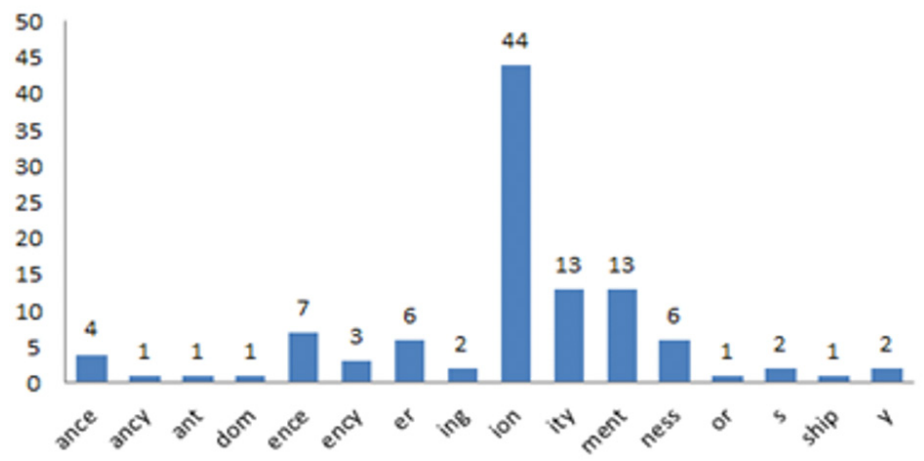

Figure 2. Noun Suffix

\subsection{Intermediate-Frequency Affixes}

Intermediate-frequency affixes refer to the affixes used more than 50 times but less than 100 times. They can be divided into three types: -ly, -s, -al, -able, -ful, etc.

\subsection{1 -ly}

The frequency of -ly is 97 times. The most often used adverb is secondly, which is used 51 times. The other ordinal number firstly is used 37 times. The reason why firstly is used less than secondly is that firstly can be altered by other words and phrases, such as first of all, above all, in the first place, etc.

The other used adverbs are easily, daily, thirdly, really, finally, especially, roughly, quickly, widely, recently, totally, obviously, usually, gradually, lastly, rapidly, actually, clearly, firmly, hardly, importantly, deeply, eventually, greatly, increasingly, especially, carefully, certainly, immediately, universally, etc.

\subsection{2 -s}

Affix in terms of third-person singular(-s) is used 87 times. The most often used word is makes which is used 16 times. Comes is used 15 times. Means is used 13 times. The other used word examples are does, continues, functions, goes, studies, contains, develops, minds, follows, plays, replaces, costs, knows, seems, appears, becomes, gives, happens, provides, refers, shows, agrees, attaches, believes, features, helps, influences, likes, needs etc. Errors can also be found such as 'developes' that is caused by falsely take -es as an inflectional affix.

4.2 .3 -al, -able, -ful, etc

Affixes in terms of adjective suffixes are used 81 times, including suffixes like -al, -able, -ful, -ive, -ous. The frequency of each adjective suffix is listed in Figure 3. The most often used word is traditional that is used 188 times. The second comes the word reliable that is used 33 times. The third is the word expensive that is used 27 times. The adjectives ending with -al have many other examples such as traditional, environmental, economical, industrial, personal, financial, regional, critical, cultural, emotional, functional, historical, etc. The word 'electronical' is wrongly used as an adjective. The right form of the word should be used as an adverb, 'electronically'.

The other words of adjective suffixes are as follows: reliable, expensive, affordable, useful, comfortable, harmful, economic, healthy, beautiful, suitable, helpful, enjoyable, useless, careful, meaningful, wonderful, colorful, realistic, successful, valuable, acceptable, accessible, attractive, countless, endless, favorable, impressive, 
continuous, contradictory, creative, dangerous, different, disadvantageous, unjoyful, expansive, fabulous, foreseeable, etc.

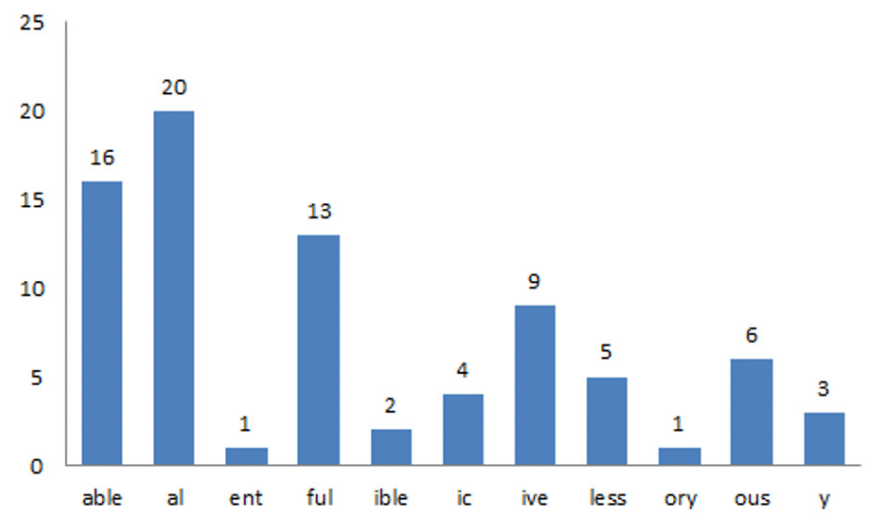

Figure 3. Adjective Suffix

\subsection{Low-Frequency Affixes}

Low-frequency affixes refer to the affixes used less than 50 times. They can also be divided into two types: im-, in-, ir-, etc., and -er, -en, -est.

4.3.1 im-, in-, ir-, etc

Affixes in this group are all prefixes which are used 25 times in 174 compositions. Examples in this group are impossible, inappropriate, incomparable, inconvenient, inconvenient, incorrect, indifferent, indispensable, irrelevant, irreplaceable, irrevocable, misunderstood, unable, uncomfortable, undeniably, undoubted, unfair, unforgettable, unfortunately, unhealthy, unlimited, unnecessary, unreasonable, unusual. Affixes in terms of negation are im-, in-, ir-, mis-, un-. Among these prefixes, the most often used is un-, next is in-. It suits the prefix order put forward by Wu Yi \& Ma Guanghui (2006).

\subsection{2 -er, -en, -est}

There are some other affixes that are used in a low frequency. Comparative form -er is used 22 times, such as cheaper, clearer, deeper, easier, faster, fewer, former, greater, healthier, heavier, higher, larger, later, longer, lower, older, quicker, safer, slower, smaller, sooner, weaker.

Verb suffix here refers to -en and it is used only 5 times. Those words are broaden, deepen, fallen, lighten, strengthen. Superlative form (-est) is used only once. The word contains -est is largest.

\subsection{Summary}

Besides these, there are many irregular changes, like past tense, past participle, noun plurality, comparative form, and third-person singular(-s).

The results can be summarized as follows. Although college students have learned English in middle school and junior high school for more than 6 years and have even been taught to study English as English majors in college, the flexibility and accuracy of affixes still have a long way to go. The most often used affix is $-s$ or -es, which is a simple suffix that has no complicated changes. Derivative affixes, such as different kinds of prefixes, which can help to express various kinds of meanings, are rarely used. Even though some of them have used prefixes, only limited in negative prefixes, like -un, -in, -ir. Spelling mistakes still account for a high proportion, it can be seen that students are not able to acquire the most basic affix knowledge.

Besides, the lack of English writing training is an important point. In the first college year, English majors have writing courses. They write compositions more often than the other two grades do. Therefore, students should be aware of improving their English writing ability and practice writing compositions now and then. At the same time, teachers should also pay attention to increase students' writing practices and help them to get into a good habit of double-checking and form a strict thinking pattern.

\section{Conclusions}

This part will put more emphasis on the conclusion drawn from the previous investigation and analysis. Then, the pedagogical implications of the present empirical study will be presented. Furthermore, this section will also find some limitations. 


\subsection{Findings}

The use of affixes by Chinese English learners is clear. It can be divided into three different categories: (1) High-frequency affixes, such as $-s$, -ed, -ing, -ion, -ity, -ment, etc. (2) Intermediate-frequency affixes, such as -ly, -al, -able, -ful, -ive. (3) Low-frequency affixes, such as im-, in-, ir-, mis-, un- and so on. Among all the affixes, $-s$ or -es ranks the first, $-d$ or-ed ranks the second and -ing ranks the third. The flexibility and precision of the affixes are not satisfactory. The most often used affix is $-s$ or -es, which is a simple suffix that has no complicated changes. The use of derivative affixes is quite rare. Even though some of them have used prefixes, only negative prefixes are used. Worse still, spelling mistakes still account for a high proportion. It can be seen that students are unable to acquire the most basic affix knowledge.

The use of a self-built corpus can provide teachers with more real and timely feedback on the target students. It can be used to discover the weak points when they are studying a second language as well as find out typical mistakes that students make in writing. At the same time, teachers can find their deficiencies in instruction to better promote the instruction quality of writing class. Therefore, most educators and professors should vigorously develop and utilize it to promote college English instruction in language writing. In addition, teachers could introduce more affix knowledge and some other ways to help remember vocabulary in writing class.

\subsection{Limitations}

However, as an exploratory study, there are still many deficiencies that need to be improved. They are shown as the following aspects:

First, there are some words lost during the process of collecting and processing data. Even though many efforts have been made to ensure valid words, it is still hard to make sure every word is one hundred percent correct by hand-editing work. Besides, it is possible that software might occasionally produce errors.

Second, it should be noted that due to time limitations, we only adopted a cross-sectional approach that analyzes the present situation of affix acquisition in different students' English level. To observe the development in the acquisition of affixes, it would be better to combine a cross-sectional approach with a longitudinal study. That is to say, it is necessary to follow a group of subjects for at least one year and do the experiment on them during different stages.

In conclusion, the present study could throw light on the future study of this kind and also for those who are interested in this field.

\section{References}

Chen, Jie. (2017). A research of the plural in English countable nouns for high school students. MA thesis, Minnan Normal University.

Cui, Yanyan, \& Wang, Tongshun. (2005). A corpus-based study of Chinese EFL learners' acquisition of derivational affixes. Foreign Language Learning Theory and Practice, 2, 5-11.

$\mathrm{Hu}$, Xia. (2007). Corpus-based vocabulary teaching in HVTE education-a pilot study. MA thesis, Beijing Jiaotong University.

Laufer, B. (1986). Possible changes in attitude towards vocabulary acquisition research. International Review of Applied Linguistics, 24(1), 69-75.

Leontjev, D., Huhta, A., \& Mäntylä, K. (2016). Word derivational knowledge and writing proficiency: How do they link? System, 59, 73-89. https://doi.org/10.1016/j.system.2016.03.013

Li, Xu. (2010). A corpus-based study of English verbal suffixes. MA thesis, Dalian University of Technology.

Liu, Shaolong. (2001). Exploring word knowledge and its acquisition patterns: An experimental study of word meaning and affix. Foreign Language Teaching and Research, 33(6), 436-441.

Liu, Shaolong. (2002). Dimension development and acquisition patterns of L2 word knowledge. Journal of PLA University of Foreign Languages, 25(2), 66-69.

Mochizuki, M. (1998). Understanding English affixes by Japanese learners. Reitaku Review, 4, 100-120.

Mochizuki, M., \& Aizawa, K. (2000). An affix acquisition order for EFL learners: An exploratory study. System, 28(2), 291-304. https://doi.org/10.1016/S0346-251X(00)00013-0

Nagy, W. E., Diakidoy, I. A. N., \& Anderson, R. C. (1993). The acquisition of morphology: Learning the contribution of suffixes to the meanings of derivatives. Journal of reading Behavior, 25(2), 155-170. https://doi.org/10.1080/10862969309547808 
Nation, S. P. (1990). Instruction and learning vocabulary. New York: Newbury House Publishers.

Peng, Tingting. (2009). Review on empirical studies of affix acquisition. Journal of Tangshan Teachers College, 31(1), 26-29.

Richards, J., \& Richard Schmidt. (2003). Longman Dictionary of Language instruction and Applied Linguistics. An Imprint of Pearson Education.

Schmitt, N. (1998). Tracking the incremental acquisition of second language vocabulary: A longitudinal study. Language learning, 48(2), 281-317. https://doi.org/10.1111/1467-9922.00042

Schmitt, N., \& Meara, P. (1997). Researching vocabulary through a word knowledge framework: Word associations and verbal suffixes. Studies in second language acquisition, 19(1), 17-36. https://doi.org/10.1017/S0272263197001022

Tabatabaei, O., \& Yakhabi, M. (2011). The Relationship between Morphological Awareness and Vocabulary Size of EFL Learners. English Language Teaching, 4(4), 262-273. https://doi.org/10.5539/elt.v4n4p262

Wang, Shizheng. (2008). The interaction of phonological constraints on English -IZE suffixation. MA thesis, Dalian University of Foreign Languages.

Wu Yi, \& Ma Guanghui. (2006). The research of affix acquisition of Chinese English learners. Jiangsu Foreign Language Teaching and Research, (2), 6-9.

$\mathrm{Wu}$, Yi. (2007). The study of English affix acquisition order of Chinese English learners. MA thesis, Nanjing Normal University.

Wu, Zhifang. (2007). Case analysis of English vocabulary teaching in vocational colleges-Take promote corpus as an example. Businesses Economic Review, (2), 164-166.

$\mathrm{Xu}$, Shuling. (2011). The application of corpus in English vocabulary teaching in higher vocational colleges. Journal of Southwest Agricultural University, (9), 212-213.

Zhang, D., \& Koda, K. (2013). Morphological awareness and reading comprehension in a foreign language: A study of young Chinese EFL learners. System, 41(4), 901-913. https://doi.org/10.1016/j.system.2013.09.009

Zhao, Ming. (2014). A study on the relationship between affix acquisition and second language level of Chinese English learners. MA thesis, Ludong University.

\section{Copyrights}

Copyright for this article is retained by the author(s), with first publication rights granted to the journal.

This is an open-access article distributed under the terms and conditions of the Creative Commons Attribution license (http://creativecommons.org/licenses/by/4.0/). 